Fanum

Sociológico
Forum Sociológico

Série II

17 | 2007

Envelhecimento activo. Um novo paradigma

\title{
Jack Barbalet (1998/2001). Emotion, Social Theory, and Social Structure. A Macrosociological Approach. Cambridge University Press
}

Sofia Amândio

\section{OpenEdition}

Journals

Edição electrónica

URL: https://journals.openedition.org/sociologico/1690

DOI: 10.4000/sociologico.1690

ISSN: 2182-7427

Editora

CICS.NOVA - Centro Interdisciplinar de Ciências Sociais da Universidade Nova de Lisboa

Edição impressa

Data de publição: 1 janeiro 2007

Paginação: 157-158

ISSN: 0872-8380

Refêrencia eletrónica

Sofia Amândio, «Jack Barbalet (1998/2001). Emotion, Social Theory, and Social Structure. A

Macrosociological Approach. Cambridge University Press», Forum Sociológico [Online], 17 | 2007,

posto online no dia 01 janeiro 2007, consultado o 31 março 2022. URL: http://

journals.openedition.org/sociologico/1690 ; DOI: https://doi.org/10.4000/sociologico.1690 


\title{
Jack Barbalet (1998/2001). Emotion, Social Theory, and Social Structure. A Macrosociological Approach. Cambridge University Press ${ }^{1}$
}

\author{
Sofia Amândio \\ Bolseira da Fundação para a Ciência e Tecnologia (aamandio@ens-Ish.fr)
}

Jack Barbalet $^{2}$ é uma referência académica internacional em teoria social das emoções. A sua obra é, sem duvida alguma, incontornável no que toca à institucionalização da sociologia das em oções como campo sub-disciplinar.

Mesmo que não seja apresentado como tal, o seu programa parece pretender combater um dos obstáculos epistemológicos mais persistentes com que a sociologia das emoções - ainda hoje - se digladia: o essencialismo (cf. Sartre, 1938). Ou seja, o sociólogo australiano opõe-se à perspectiva que vê a emoção como algo que precede o ser humano, ou como algo pré-cultural que transcende o social.

O livro Emotion, Social Theory and Social Structure, A Macrosociological Approach pretende demonstrar que a emoção merece um lugar central na investigação sociológica e na teorização: "this book explores particular emotions in order to extend our understanding of social structure, and to enhance the competence of our social theory" (p. 6-7).

No capítulo 1, "Emotion in social life and social theory" é abordada a questão da emoção na sociologia e nos processos sociais, através de uma historicização do que o autor designa como a "carreira do conceito de emoção na análise social": desde o iluminismo escocês do século XVIII; passando pelo Romantismo; pelas sociologias europeia (Weber, Pareto, Simmel...) e americana (Goffman, Cooley...) dos séculos XIX e XX; até ao final dos anos 70 e princípio dos anos 80 , período de afirmação de uma agenda de investigação para esta especialidade (Collins, Denzin, Hochschild, Kemper, Scheff ...).

O modo como o conceito de emoção é tratado nas ciências sociais é bastante plural. O livro em recensão pensa-o de múltiplas formas. Nomeadamente, de dois pontos de vista distintos: a emoção estudada como causa, e a emoção como consequência. De acordo com a visão dominante, a emoção é uma consequência do cultural e do cognitivo. Esta visão social construtivista entende a emoção como um resultado, um efeito ou um produto dos processos sociais. A emoção como uma "coisa" é explorada por exemplo por Hochschild. Por outro lado, a emoção como causa dos processos sócio-estruturais e rela- cionais é uma visão menos aceite, e é, por exemplo, adoptada por Kemper ou Scheff.

Barbalet adopta também esta última perspectiva, tendo na emoção uma variável explicativa para o fundamento do comportamento humano: "The only good reason to offer a sociological explanation of emotion is if emotion is itself significant in the constitution of social relationships, institutions, and processes" (p. 9). O autor prossegue, afirmando que enquanto a emoção em geral é uma categoria abstracta, a experiência ocorre sempre ao nível das emoções particulares. A particularidade de uma em oção deve pois ser localizada nas suas causas e consequências sociais. Esta distinção entre causas e consequências é, logicamente, analítica, podendo ser articulada.

Antes de abrir um conjunto de capítulos em que articula várias emoções particulares, com outros conceitos sociológicos clássicos, o autor discute justamente a abordagem convencional que opõe emoção e racionalidade. O capítulo 2, "Emotion and rationality", apresenta assim um exercício de desconstrução deste par conceptual, por confronto à abordagem crítica (a emoção apresenta soluções para problemas que a razão não consegue resolver) e à abordagem radical (a emoção e razão como um continuum). Questionadas estas ideias feitas, sedimentadas ao longo dos últimos três séculos, o sociólogo passa então ao exame de emoções específicas. São desenvolvidos os seguintes temas:

"Class and resentment" (cap. 3). O autor trata aqui do significado do ressentimento na constituição das classes sociais. Barbalet procura, desta forma, resolver questões relativas à articulacão das diferentes escalas do social: "emotions have a macrosociological presence in their own right, or, more specifically ...emotion inheres simultaneously in individuals and in the social structures and relationships in which individuals are embedded" (p. 65).

"Action and confidence" (cap. 4). É aqui analisada a base emocional da acção e da agência: "all action ... is based upon that confidence which apprehends a possible future" (p. 82). A questão da 
temporalidade torna-se desta form a central. Segundo o autor, a confiança torna possíveis a acção presente e a projecção do indivíduo no futuro.

"Conformity and shame" (cap. 5). Este capítulo centra-se nas formas predominantes de vergonha ligadas à percepção negativa do eu (do ponto de vista do outro), que contribuem inequivocamente para a conformidade social. A vergonha narcísica ou a vergonha agressiva são, por sua vez, consideradas problemáticas para a ordem social.

"Rights, resentment, and vengefulness" (cap. 6). A simpatia, emoção frequentemente associada à obtenção de direitos básicos, tem, tal como é discutida neste capítulo, uma relação problemática com a interacção cooperativa. Bem ao contrário, o ressentimento e a vingança são pensados como factores de conquista de direitos básicos, no sentido em que significam "the emotional aprehension of a social violation of the satisfaction of a need" ( $p$. 126). Trata-se pois de factores de conquista de direitos básicos.

"Fear and change" (cap. 7). Por fim, Barbalet problematiza a mudança social e organizacional, mais concretamente, a influência do medo nos processos sociais. Enquanto o medo levado ao extremo possa ser incapacitante, a maior parte das experiências e episódios de medo não são tão extremos. O medo não é exam inado como exclusivo dos grupos dominados, dada a relevância do medo experimentado pelas elites, que constitui, segundo o autor, uma condição de mudança organizacional e institucional. Esta proposição é demonstrada com base num caso empírico, o medo sentido pela elite britânica face ao movimento dos trabalhadores, durante e após a I Guerra Mundial.

Reagindo à sociologia das emoções americana dos anos 80 , de tendência microssociólogica (cf. Toits, 1989), Barbalet adopta, deste modo, a escala das macroestruturas. A discussão do papel da emoção em macro unidades sociais e processos foca-se tipicamente em manifestações patológicas das emoções e das suas consequências destrutivas (cf. Scheff 1999/1966). Este livro incide, ao contrário, nas emoções particulares como variáveis explicativas dos processos e estruturas sociais, do ponto de vista da ordem social e da norma. São, neste sentido, emoções necessárias às estruturas da ordem social, fundamentais à mudança social não revolucionária.

Constatamos, assim, que este livro nos afasta do risco de essencialização do conceito de 'em oção'. Não obstante, este não sai ileso de uma outra crítica: a ausência de vertente empírica. O seu carácter eminentemente teórico poderá, de facto, ser bastante atractivo aos olhos da crítica mais rápida. É certo que a sociologia das emoções tem uma tradição mais teórica que empírica (mesmo sem esquecer, por exemplo, as fundamentações empíricas de Goffman, ou o trabalho de campo de Hochschild), e que Barbalet não se propõe ir contra a corrente. Mas a teoria sociológica, enquanto reflexão sobre conceitos teóricos ou teórico-empíricos, é um campo de investigação com tradição académica legítima na sociologia anglo-saxónica que integra. Para além do mais, a definição de emoções particulares é feita sem nunca se deixar cair a sua variabilidade histórica, sendo fornecidos exemplos de episódios diacronicamente determinados. Esta abordagem só tem a beneficiar, em nosso entender, os investigadores que a queiram operacionalizar nos mais diversos contextos sociais.

Por tudo isto, podemos dizer sem hesitação que o problema da ausência de uma linguagem descritiva das emoções, a que Pierre Bourdieu aponta o dedo nos anos 70 (Pinto, Sapiro e Champagne, 2004) perde hoje alguma razão de ser. Este livro constitui, de facto, um contributo singular ao trabalho de codificação teórica das emoções, no sentido da sua consistência terminológica. É certamente um futuro clássico.

\section{Notas}

1 Este livro foi traduzido para português pelo Instituto Piaget, em 2001, sob o título Emoção, Teoria Social e Estrutura Social - Uma Abordagem Macrossocial.

2 Jack Barbalet é hoje Foundation Professor na University of Western Sidney, após ter desempenhado durante oito anos a função de director do Departamento de Sociologia da University of Leicester (1999-2008). Jack Barbalet foi também o primeiro presidente da Sociology of Emotions Research Network 11, da European Sociological Association, constituida em Maio de 2004. Entre outras publicações, contam-se o livro que editou em 2002, Emotions and Sociology, ou, publicado em Julho 2008, Weber, Passion and Profits: 'The Protestant Ethic and the Spirit of Capitalism' in Context.

\section{Referências}

PINTO, L., G. Sapiro, P. Champagne (2004), Annexe. "Entretien de Pierre Bourdieu avec Gisèle Sapiro, le 7 juin, 2000", Pierre Bourdieu, Sociologue. Paris, Fayard, pp. 83-84.

SARTRE, J.-P (1965/1938), Esquisse d'une Théorie des Emotions, Paris, Hermann.

SCHEFF, T., (1999/1966), Being Mentally III: A Sociological Theory, Aldine Press.

THOITS, P. (1989), "The Sociology of Emotions", Annual Review of Sociology, Vol 15, 317-342. 